\title{
The backscatter cloud probe - a compact low-profile autonomous optical spectrometer
}

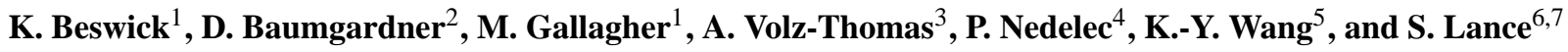 \\ ${ }^{1}$ University of Manchester, Manchester, UK \\ ${ }^{2}$ Droplet Measurement Technologies, Boulder, CO, USA \\ ${ }^{3}$ Forschungszentrum Jülich $\mathrm{GmbH}$, Institut für Energie und Klimaforschung 8: Troposphäre, 24525 Juelich, Germany \\ ${ }^{4}$ CNRS Laboratoire d'Aérologie, Univerity of Toulouse, Toulouse, France \\ ${ }^{5}$ Department of Atmospheric Sciences, National Central University, Chung-Li, Taiwan \\ ${ }^{6}$ Earth System Research Laboratory, National Oceanic and Atmospheric Administration, Boulder, CO, USA \\ ${ }^{7}$ Cooperative Institute for Research in Environmental Sciences, University of Colorado, Boulder, CO, USA
}

Correspondence to: D. Baumgardner (darrel.baumgardner@gmail.com)

Received: 16 June 2013 - Published in Atmos. Meas. Tech. Discuss.: 16 August 2013

Revised: 17 March 2014 - Accepted: 31 March 2014 - Published: 23 May 2014

\begin{abstract}
A compact $\left(500 \mathrm{~cm}^{3}\right)$, lightweight $(500 \mathrm{~g})$, nearfield, single particle backscattering optical spectrometer is described that mounts flush with the skin of an aircraft and measures the concentration and optical equivalent diameter of particles from 5 to $75 \mu \mathrm{m}$. The backscatter cloud probe (BCP) was designed as a real-time qualitative cloud detector primarily for data quality control of trace gas instruments developed for the climate monitoring instrument packages that are being installed on commercial passenger aircraft as part of the European Union In-Service Aircraft for a Global Observing System (IAGOS) program (http://www.iagos.org/). Subsequent evaluations of the BCP measurements on a number of research aircraft, however, have revealed it capable of delivering quantitative particle data products including size distributions, liquid-water content and other information on cloud properties. We demonstrate the instrument's capability for delivering useful long-term climatological, as well as aviation performance information, across a wide range of environmental conditions.

The BCP has been evaluated by comparing its measurements with those from other cloud particle spectrometers on research aircraft and several BCPs are currently flying on commercial A340/A330 Airbus passenger airliners. The design and calibration of the BCP is described in this article, along with an evaluation of measurements made on the research and commercial aircraft. Preliminary results from more than $7000 \mathrm{~h}$ of airborne measurements by the $\mathrm{BCP}$ on
\end{abstract}

two Airbus A340s operating on routine global traffic routes (one Lufthansa, the other China Airlines) show that more than $340 \mathrm{~h}$ of cloud data have been recorded at normal cruise altitudes $(>10 \mathrm{~km})$ and more than $40 \%$ of the $>1200$ flights were through clouds at some point between takeoff and landing. These data are a valuable contribution to databases of cloud properties, including sub-visible cirrus, in the upper troposphere and useful for validating satellite retrievals of cloud water and effective radius; in addition, providing a broader, geographically and climatologically relevant view of cloud microphysical variability that is useful for improving parameterizations of clouds in climate models. Moreover, they are also useful for monitoring the vertical climatology of clouds over airports, especially those over megacities where pollution emissions may be impacting local and regional climate.

\section{Background}

Reliable predictions of the future climate, using ever improving climate models, are fundamental requirements for determining future mitigation strategies. The need for 3-D global data sets is increasing, particularly in those regions of the atmosphere where satellites are technically limited. Use of commercial aircraft now allows the collection and transmission of highly relevant observations on a scale and 
in numbers impossible to achieve using normal research aircraft. The European Research Infrastructure program IAGOS (In-service Aircraft for a Global Observing System) has therefore been developed with the aim of establishing a distributed infrastructure comprising a fleet of 10-20 longrange, in-service aircraft of internationally operating airlines for long-term observations of atmospheric composition, on global scales, to address the growing need of the global modeling community. The project, led by the Forschungszentrum Jülich, and in collaboration with Airbus and commercial carriers, has developed several miniature modular instrument packages for commercial Airbus A330/A340 passenger aircraft. These modular, expandable platforms currently include measurements of aerosol particle concentrations, reactive and greenhouse gases and, the focus of this article, cloud particle concentrations. Whilst the scientific community has learned a great deal about cloud microphysical processes and cloud radiative effects over the last few decades, most of the current global cloud data sets are either in situ measurements from short-term field experiments or remote-sensing data products, for example, ISCCP, (International Cloud Satellite Cloud Climatology Project) established in 1982 as part of the World Climate Research Program. Currently the data products available to the community include cloud amount, cloud type and cloud top temperature as well as optical thickness based on radiance. More specific retrieved microphysical properties include effective liquid-water and ice-crystal particle radius which have been validated against a wide range of WCRP and GEWEX field campaigns (e.g., GEWEX Cloud System Study Data Integration for Model Evaluation (GCCS-DIME) program). Typical uses for such global cloud data products are described by Rossow et al. (2005), who use cluster analysis techniques to investigate links between multi-variate relationships between clouds, mesoscale meteorological processes and global and regional energy-water budgets. Such studies are normally constrained to large fields of view and the inherent variability on sub-satellite, sub-grid scales are lost. Field campaigns to study these sub-grid scale processes, however, are expensive and time consuming to mount and are often time limited. In this respect a continuous, real-time, in situ observing system can make a contribution by providing key data products.

Commercial aircraft are limited in the types of clouds that they can sample, for example, convective cells that they would normally try to avoid or low lying, marine stratiform clouds. They do, however, fly most of their time at altitudes where they encounter many types of cirrus, a cloud type that is important for climate modulation and that can sometimes be difficult to measure with satellites. In addition, although they do not do vertical profiles of clouds, such as those done with research aircraft, their take offs and landings are often through a variety of cloud types.
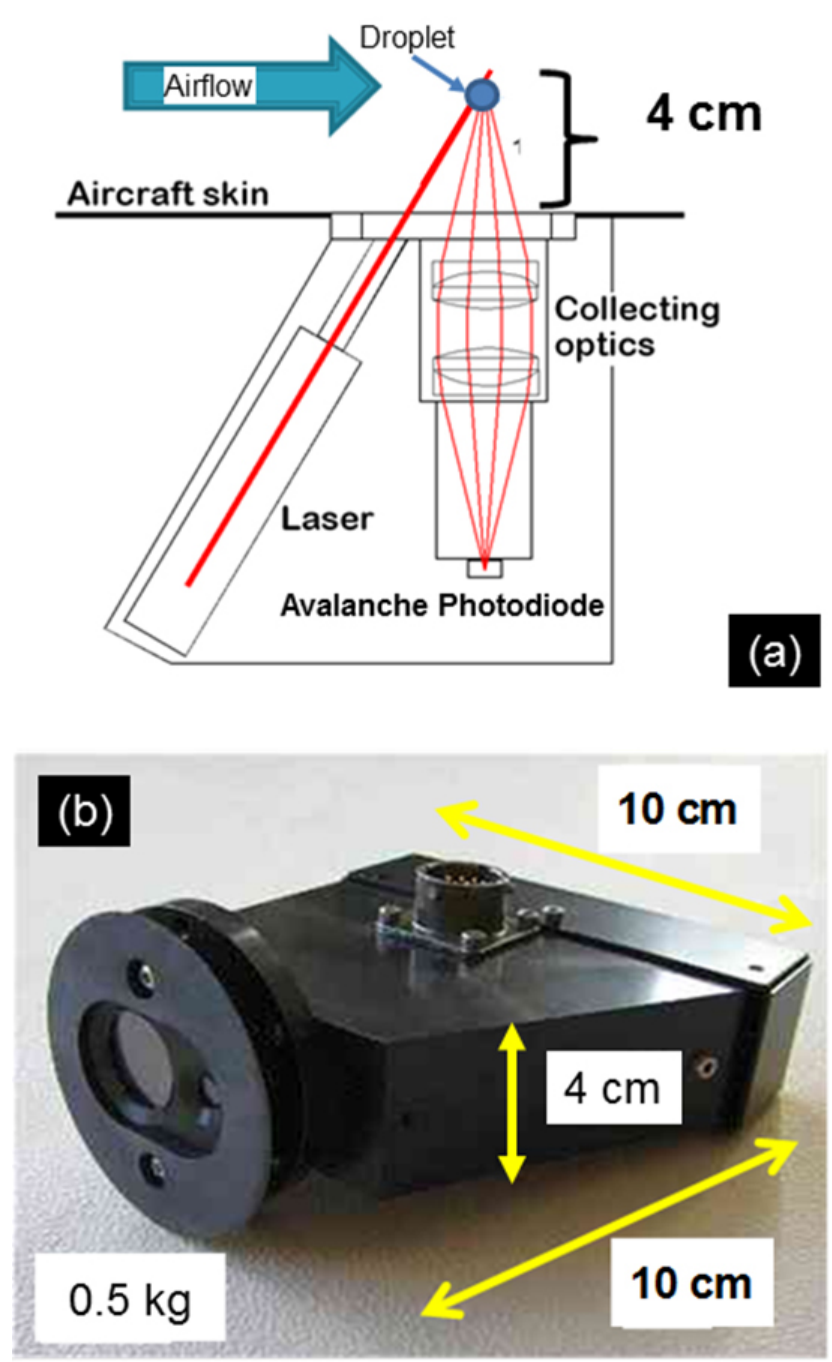

Figure 1. The optical layout of the backscatter cloud probe (BCP) is shown in the top panel illustrating the principal components. The lower panel is a photograph of the BCP that shows the relative dimensions.

\section{The backscatter cloud probe}

\subsection{Design and operating principals}

The BCP optical layout, as shown in Fig. 1a, consists of a laser diode that produces focused, linearly polarized light at a wavelength of $658 \mathrm{~nm}$. The laser beam is transmitted through a fused, heated (to eliminate fogging) silicate glass window and focused on a small region approximately $4 \mathrm{~cm}$ from the window. Particles that pass through the sample volume scatter light with an intensity proportional to the size, refractive index and shape of the particle and the collection angle with respect to the incident beam. The fraction of light that is scattered backward at a solid angle of $144-156^{\circ}$ is collected by a set of lenses that are located behind the window. These focus the collected light onto an avalanche photodiode (APD). 


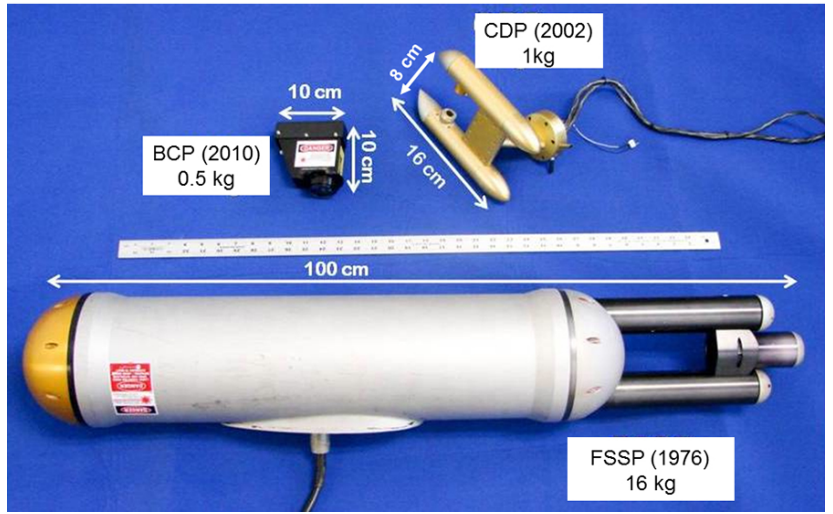

Figure 2. This photograph compares the backscatter cloud probe (BCP) with the forward scattering spectrometer probe (FSSP) and the cloud droplet probe (CDP) that were introduced 38 and 12 years ago, respectively.

The collection angles were determined by the geometry of the system that was designed to keep the laser as close to the collection optics as possible so that the overall package would remain small. The sensitive sample area of the beam, as well as the collection angles, is determined by the width of the laser beam at the center of focus of the optics and the diameter of the lens.

The photons that strike the APD are converted into a current that the signal conditioning electronics change to a voltage signal. These electronics also filter electronic noise and remove offsets due to capacitance in the electronic circuit. When the transient signal exceeds the minimum threshold, set just above the electronic noise level the peak voltage is detected and digitized by a 4096 bit analog to digital converter. Particles whose peaks exceed the range of the amplifiers are rejected. The value of this peak is used to select which size channel to increment by one count. The thresholds of these channels are set based upon calibrations and theory. In addition to creating the size distribution of ADC, various voltages and temperatures, "housekeeping" parameters, are measured for monitoring the health of the instrument. The size distribution and housekeeping parameters are transmitted serially when given a command by a data system. The sampling rate is determined by the data system that sends the flag to the $\mathrm{BCP}$ to transmit the data. The BCP can be programmed to generate $10,20,30$ or 40 channel size distributions

The compact, simple design of the BCP optical head, which weighs only $500 \mathrm{~g}$ and takes up a volume of less than $500 \mathrm{~cm}^{3}$, allows it to be mounted easily. Thousands of hours of flying on commercial aircraft show that it requires infrequent maintenance. Figure $1 \mathrm{~b}$ is a photo of the the $\mathrm{BCP}$ and Fig. 2 shows the BCP compared to two other single particle optical spectrometers; the cloud droplet probe (CDP), which was introduced in 2002, and the forward scattering spectrometer probe (FSSP), developed in 1976. This comparison illustrates how state of the art optics and electronics has allowed

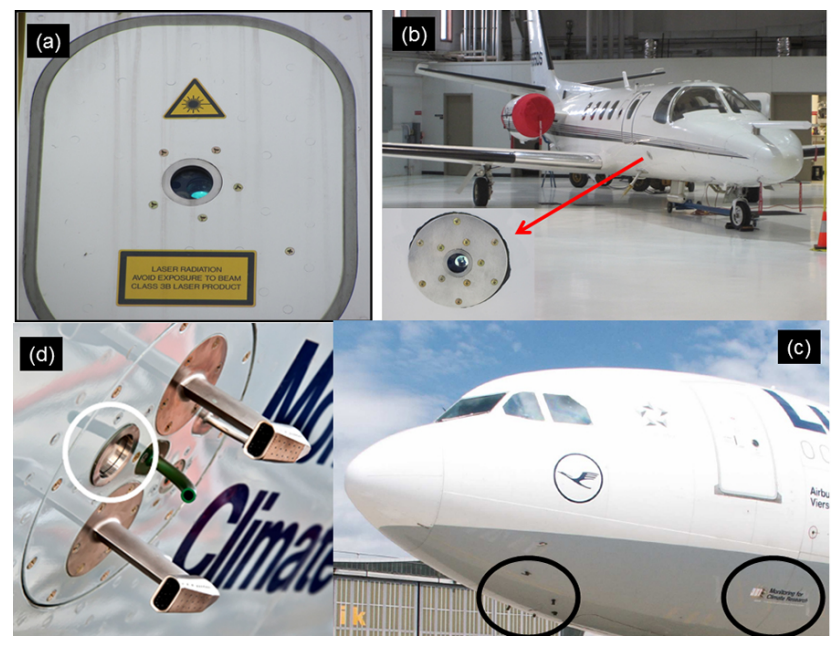

Figure 3. The backscatter cloud probe (BCP) is mounted with its window looking out through a transparent aperture as illustrated in these four photos, clockwise: (a) on an access hatch of the FAAM BAE-146; (b) on a hard point just behind the co-pilot and just ahead of the emergency exit of the University of North Dakota Cessna Citation, inside the radio compartment; and (c) on a Lufthansa A340300 Airbus just behind and below the forward passenger access door - (d) a close-up photo of the BCP window on the Airbus.

the scaling down in size and weight of cloud spectrometers. One of the disadvantages of the BCP is that the laser is not eye-safe and so precautions are needed so as not to operate it under conditions where it could be a potential hazard. The next generation BCP, under development, will use an eyesafe laser.

The BCP mounts on the aircraft interior looking out through a transparent aperture. Figure 3 shows several photos of BCP installations on the hatch of the Facility for Airborne Atmospheric Measurements (FAAM) BAE-146, on the nose of the University of North Dakota Citation and near the nose of the Lufthansa "Veirsen" A340-300 Airbus. A pressurized bulkhead is not required as the instrument is designed to operate up to $20 \mathrm{~km}$ altitude, $\pm 60^{\circ} \mathrm{C}$ and $100 \%$ humidity. The optical head and processing electronics are separate units connected by a cable. Interfacing to the data logger is via a standard RS-232 serial cable. The BCP can operate on $110 / 220$ AC or $24 \mathrm{~V}$ DC.

The BCP was designed to meet the specifications of the In-Service Aircraft for a Global Observing System (IAGOS) program. The BCP was originally intended as a simple indicator of the presence of cloud to aid in analyzing the gas measurements that are part of the IAGOS package. Knowing when the aircraft is flying through cloud is important when interpreting measurements of water vapor, ozone, and carbon monoxide. The $\mathrm{BCP}$ was designed with the same detection principles as other single particle cloud spectrometers, that is, to derive optical diameters based upon the intensity of light scattered by a particle. Hence, it not only indicates the 

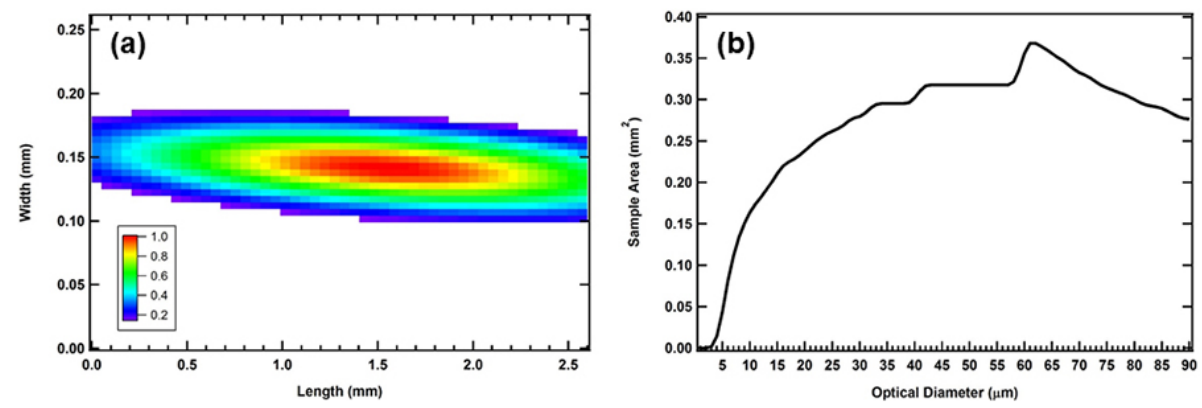

Figure 4. (a) This contour plot shows the normalized scattering intensity across the sensitive sample area of the backscatter cloud probe (BCP). The contours values are the ratio of scattering intensity to the maximum value. (b) The sample area as a function of droplet diameter is shown in this figure.

presence of a cloud but also provides additional information about the cloud microphysical properties via distributions as a function of size of number and mass concentrations.

\subsection{Calibration}

The BCP sample area is measured using the calibration system described by Lance et al. (2010), which generates a highly mono-disperse droplet stream using a piezo-electric droplet generator device and transmits the droplets across precise locations of the $\mathrm{BCP}$ laser beam. The $\mathrm{BCP}$ response characteristics are mapped by moving the calibration system relative to the instrument using linear translation stages with differential positioning precision of $10 \mu \mathrm{m}$. The maximum light scattering intensity registered by the $\mathrm{BCP}$ is monitored. An intensity map is created by rastering along and across the laser beam such as the one shown in Fig. 4a. This color map is a normalized, two-dimensional Gaussian fit to the 52 measurements. The colors represent the relative intensity of scattering from the particles, where red is maximum and blue is minimum. The scattering intensity at each grid point was divided by the maximum scattering intensity to produce the normalized values. The mapping of the beam also provides a measure of the sensitive sample area of the BCP. The area is derived by summing the total number of grid points in the scan. The sensitive area for the $22 \mu \mathrm{m}$ droplets that were used to map the beam was $0.25 \mathrm{~mm}^{2}$. The sample area depends on the size of the droplet, i.e., smaller droplets will be detected within a smaller area than larger droplets because of the intensity distribution of the laser beam. Ideally, each $\mathrm{BCP}$ should have its beam scanned using the full size range of droplets that can be measured. This might be possible using a fully automatic scanning system, but the current system requires manual operation and mapping from 5-75 $\mu \mathrm{m}$, the current size range of the BCP, would require many days. Hence, the size dependent sample area can be estimated using the single map of normalized intensity values. Each grid point represents what fraction of the maximum light would be scattered by a droplet when passing through region of the beam represented by that grid point. For example, if a $10 \mu \mathrm{m}$ droplet scattered a maximum amount of light at the center of the beam of 3000 analog to digital counts (ADC), then farther away from the center, it might go through a part of the beam where it would only scatter $50 \%$ of the maximum, or $1500 \mathrm{ADC}$. As long as the intensity of scattered light is above noise level, $50 \mathrm{ADC}$ in the case of the $\mathrm{BCP}$, the droplet will be detected, albeit undersized. Figure $4 \mathrm{~b}$ shows the sample area as a function of the droplet diameter. These areas were calculated by converting the theoretical scattering cross section of a droplet of a specific size, derived with Mie (1908) theory, to equivalent ADC, derived from calibrations. These ADC were multiplied by the normalized fraction of maximum scattering at each grid point. If the result of the multiplication was greater than 50 then the area of this grid point was added to the total to produce the final sample area for that diameter of droplet.

The droplet diameter is derived from the "glare" technique (Korolev et al., 1991; Wendisch et al., 1996; Nagel et al., 2007), in which specular reflections off the front and back face of droplets are observed by a camera. These droplets of known diameter are used to to calibrate the BCP for size using Mie (1908) theory. The scattering cross section provides the relationship between the voltage, $V_{0}$, produced by the photodetector and associated electronics, and the scattered light intensity, $I_{0}$. The scale factor $S=I_{0} / V_{0}$ is used to calculate scattering cross sections from the measured peak voltages. The value of $V_{0}$ is obtained when the calibration water droplet passes through the maximum beam intensity.

As an idealized example, if the laser intensity within the sensitive sample area is uniform and homogeneous in intensity, then to derive the optical diameter of a cloud droplet, all that is needed is the measured voltage, $V$, multiplied by $S$ to obtain a scattering cross section, $I$, that is associated with a diameter of droplet, $D$; however, due to the non-uniform intensity of the laser beam, as well as the non-monotonic relationship between particles and their scattering cross section in the Mie scattering region, a more complex procedure is needed to retrieve the particle sizes 
The intensity distribution across and along the diode laser beam is approximately Gaussian such that when a particle passes through the beam, within the viewing volume that is defined by the collection optics, it has the probability of passing through different beam intensities (i.e., particles with the same optical diameter can scatter different amounts of light due to the intensity variation).

In a cloud with a range of droplet sizes, the measured size distribution will represent the sum of the probability distributions of each particle size category determined by the probabilities that a particle will pass through a specific intensity region of the beam. Given that we have an accurate measurement of the intensity distribution across the sensitive beam area, we are faced with the classic inversion problem of estimating the actual size distribution from that which is measured.

\subsection{Size distribution retrieval by inversion}

The derivation of size distributions from the backscatter measurement involves the procedure, best known as inversion, in which we assume that the operating principle of the measurement system is well known and can be modeled such that we can predict how it will reproduce the actual size distribution. Mathematically, the actual size distribution, with $n$ size bins, is represented by the row vector $\boldsymbol{A}$. The measured size distribution, with $m$ size bins is represented by the column vector, $\boldsymbol{M}$. The $\boldsymbol{n} \times \boldsymbol{m}$ matrix, T, is a probabilistic description of how the instrument will actually measure a particle of size $\boldsymbol{i}$. Stated differently, the matrix $\mathbf{T}$ describes the probability that a particle in size element $i$ will actually be placed by the measurement into size element $\boldsymbol{j}$, where $\boldsymbol{j} \leq \boldsymbol{i}$. The relationship between $\boldsymbol{A}$ and $\boldsymbol{M}$ is expressed as

$$
\boldsymbol{M}=\mathbf{T} \boldsymbol{A} .
$$

This is solved analytically by multiplying both sides of Eq. (1) by the inverse of $\mathbf{T}, \mathbf{T}^{-1}$ :

$\mathbf{T}^{-1} \boldsymbol{M}=\mathbf{T}^{-1} \mathbf{T} \boldsymbol{A}=\boldsymbol{A}$.

This can be done only if the inverse of $\mathbf{T}$ can be calculated, an operation that is not usually possible in problems such as the one being posed in this application. The alternative solution is to implement an iterative process in which we propose a value for the actual distribution, calling it $\boldsymbol{A}^{*}$, multiply it by our transformation matrix, $\mathbf{T}$, and obtain a size distribution, $\boldsymbol{M}^{*}$, that we compare with our measured distribution, $\boldsymbol{M}$. If $\boldsymbol{M}^{*}=\boldsymbol{M}$, then $\boldsymbol{A}^{*}=\boldsymbol{A}$. Otherwise we need to adjust our value of $\boldsymbol{A}^{*}$ and recalculate $\boldsymbol{M}^{*}$. We continue this iteration until we obtain an $\boldsymbol{M}^{*}$ that is a reasonable approximation to $\boldsymbol{M}$ (i.e., when the difference between the two vectors is within a preset value).

In order to converge on the best estimate of $\boldsymbol{A}$, we need an efficient method for making the first guess of $\boldsymbol{A}^{*}$ and adjusting each subsequent guess. There are a number of problems that must be addressed when implementing an inversion algorithm, for example the size distribution that can produce what is measured may not be unique, the iterative process might converge on a solution that produces a physically unrealistic distribution or our model of the system might not be sufficiently accurate. The inversion methodology is the subject of numerous articles and books related to deriving atmospheric properties from remote sensors like satellites and other types of multi-wavelength photometers. Probably the best known methodology in the atmospheric sciences is that described by Twomey (1977) for the inversion of multiwavelength satellite measurements to obtain the properties of aerosols. To derive the size distribution measured by the BCP, we have selected a modified version of the Twomey algorithm developed by Markowski (1987).

The BCP creates the measured size histogram with $\boldsymbol{m}$ channels spanning a nominal optical diameter range from $5 \mu \mathrm{m}$ to $75 \mu \mathrm{m}$, over fixed time intervals. The thresholds of the size bins are related to the peak measured voltage of the particles and are selected so that the width of the bins are approximately equal with respect to the optical diameter of the particles. The firmware in the BCP decides into which bin the particle's peak voltage should be classified and increments the bin by one so that at the end of the time interval there is a frequency distribution of the number of particles counted per size interval. This is the measured distribution, M.

In order to create the transformation matrix, $\mathbf{T}$, we need the probability distribution that predicts which fraction of the particles that fall in bin $\boldsymbol{j}$ should have actually been placed in bin $I$, as a result of the Gaussian intensity distribution of the laser beam. We also have to take into account that some particles with different sizes have the same scattering cross section due to the light scattering properties. As illustrated in Fig. 5, the scattering cross section, calculated here with Mie theory (Mie, 1908), does not increase monotonically with diameter. When the BCP measures the light scattered by particles in some size ranges, they will be classified in smaller size intervals, as shown in Fig. 5 by the horizontal line that crosses the curve at multiple points that represents the scattering cross section of droplets of multiple diameters. This response must also be part of the model and included in the transformation matrix.

There are other properties of cloud particles that further complicate the derivation of size distribution, for example non-spherical ice crystals will scatter light quite differently although their geometric size might be approximately the same as a water droplet of equivalent diameter. Although these properties could be included in the matrix, $\mathbf{T}$, at present we derive the transformation matrix only for the case of spherical particles with a refractive index of 1.33 (water).

The transformation matrix that describes the response of an individual $\mathrm{BCP}$ is generated by calculating the scattering cross section, with Mie scattering theory, of droplets from $5 \mu \mathrm{m}$ to $90 \mu \mathrm{m}$, in $1 \mu \mathrm{m}$ intervals, then multiplying by the 


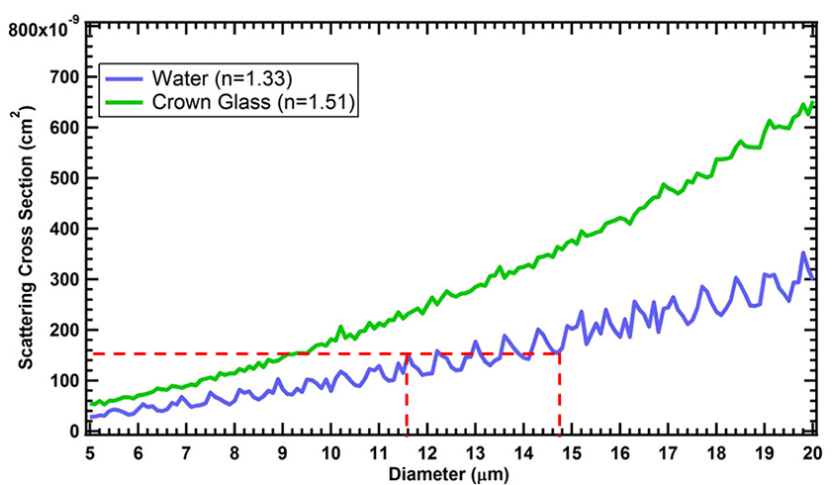

Figure 5. The theoretical response of the backscatter cloud probe is shown in this diagram that relates the scattering cross section of particles to their diameter, calculated from Mie theory assuming spherical particles, a wavelength of $685 \mathrm{~nm}$ and the refractive indices for water (1.33) and crown glass calibration beads (1.51). The red dashed line indicates an example where two particles with different diameters have the same scattering cross section and cannot be uniquely identified by their light scattering intensity.

normalized intensity map of the laser beam in order to determine into which size cells, $\boldsymbol{j}$, a particle of size, $I$, will fall. This produces a $\mathbf{T}$ matrix that is 85 rows by $\boldsymbol{m}$ columns. Figure 6 shows the probability distributions for particles with optical diameters $10,20,30$ and $40 \mu \mathrm{m}$. What is shown is the probability that a particle with the given diameter will actually be classified into a smaller size category. For example, the $40 \mu \mathrm{m}$ particle has the highest probability of being put into the $12 \mu \mathrm{m}$ size category. Some fraction of the $40 \mu \mathrm{m}$ particles will also be classified as other diameters between 5 and $40 \mu \mathrm{m}$.

Figure 7 illustrates how the measurement with the BCP is a distortion of the actual distribution, $\boldsymbol{M}^{*}$. In this figure, a theoretical Gaussian size distribution, $\boldsymbol{A}$, is generated then multiplied by the transformation matrix, $\mathbf{T}$, to calculate the hypothetical $\boldsymbol{M}$. The three curves in blue, green and magenta illustrate simulated size distributions assuming 90, 30 and 10 channels, respectively.

\subsection{Error analysis}

The BCP's primary function when it was designed was to identify the presence of cloud. Here we define a cloud in terms of the optical depth that can be derived from the extinction coefficient, $B_{\text {ext }}$. This is approximated from the measured size distribution:

$B_{\mathrm{ext}}=\pi \Sigma \theta_{\mathrm{ext}} N\left(d_{i}\right) d_{i}^{2} \cong \pi 2 N_{T} d_{\mathrm{a}}^{2}$,

where $\theta_{\text {ext }}$ is the extinction efficiency at a given wavelength, diameter and refractive index and $N\left(d_{i}\right)$ is the number concentration of cloud particles with an optical diameter of $d_{i}$. For optical diameters much larger than the incident wavelength, as will be the case for the measurements with the BCP

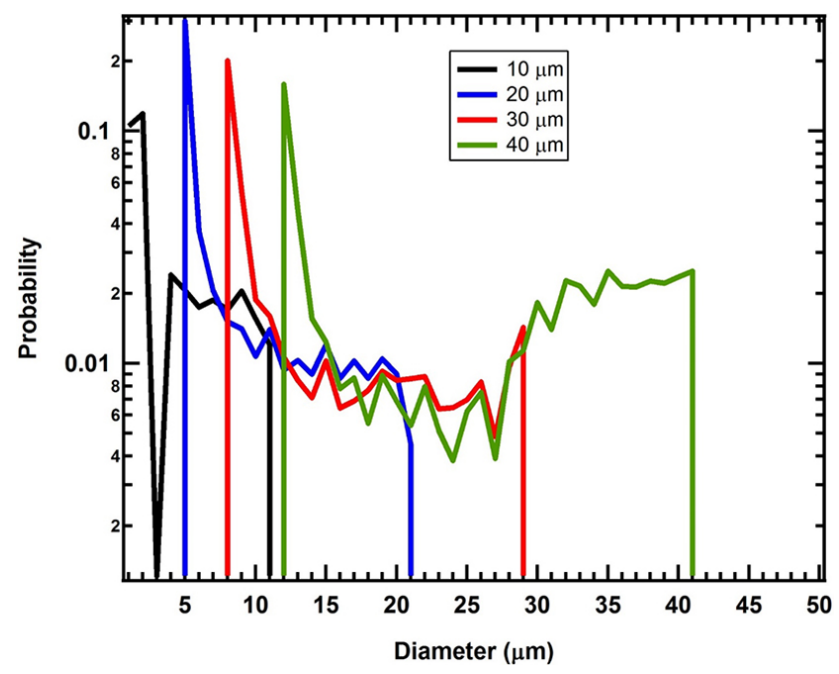

Figure 6. This figure illustrates the theoretical probability distributions for droplets with four different diameters. The probabilities are that a particle with the given size will be measured as a particle with a smaller diameter.

whose laser wavelength is $658 \mathrm{~nm}$, the value of the extinction efficiency is approximately two. We estimate the extinction coefficient from Eq. (3) as $B_{\text {ext }}=\pi 2 N_{T} d_{\mathrm{a}}^{2}$, where $N_{T}$ is the total number concentration and $d_{\mathrm{a}}$ is the area equivalent diameter.

Studies of cirrus in the last 10 years have led to the categorization of sub-visible clouds as those with optical depth, $\tau$, less than 0.03 (Sassen et al., 1989). Since the BCP's first mission is on commercial airliners whose cruise altitudes are at temperatures where only cirrus will be found, we will use 0.03 as an operational definition of a cloud to estimate the minimum concentration of cloud particles that we expect the BCP to detect. The optical depth is defined as the average extinction coefficient multiplied by the depth of the average cloud layer, $\Delta Z$ :

$\tau=B_{\mathrm{ext}} \Delta Z \cong \pi 2 N_{T} d_{\mathrm{a}}^{2} \Delta Z$.

Under the assumption of an average, area equivalent diameter $d_{\mathrm{a}}$ and cloud depth, $\Delta Z$, we can determine the number concentration of a cloud with $\tau=0.03$. For example, thin cirrus have effective diameters in the range 30-40 $\mu \mathrm{m}$ (e.g., Gayet et al., 1996). If we choose $d_{\mathrm{a}}=40 \mu \mathrm{m}$ and use a conservative value for $\Delta Z=100 \mathrm{~m}$, then $B_{\mathrm{ext}}=3 \times 10^{-6} \mathrm{~cm}^{-1}$ and $N_{T}=0.03 \mathrm{~cm}^{-3}$.

The concentration derived from the BCP measurements is determined by counting the number of cloud particles detected within the size range of the $\mathrm{BCP}$ over a selected time period and dividing by the volume of air, $V$, which passes through the sensitive sample area, SA. The volume of air is calculated as

$V=\mathrm{SA} \cdot \mathrm{TAS} \cdot T$. 


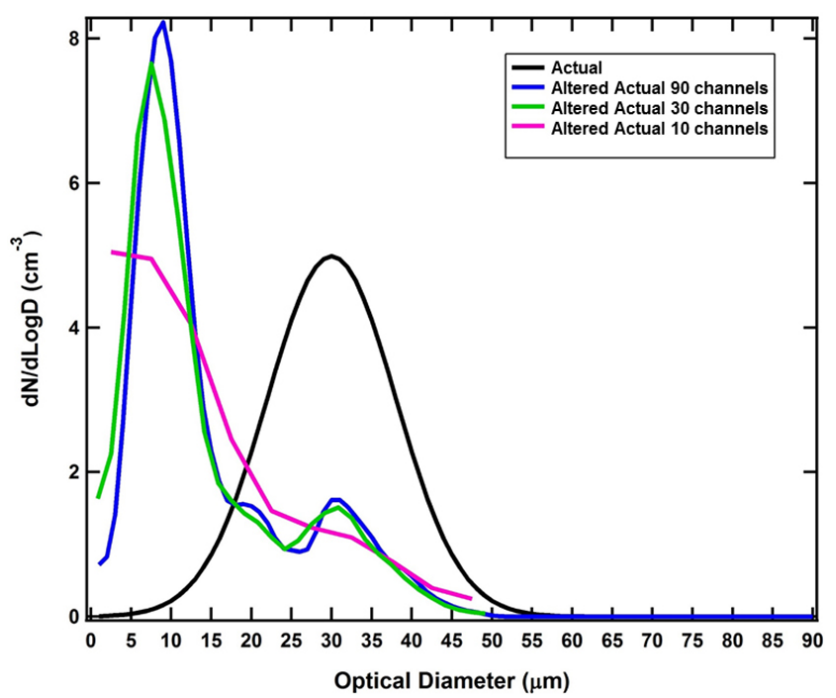

Figure 7. The distortion of the actual size distribution due to the measurement principles of the BCP are illustrated in this figure that shows a simulation of how the measured size distribution would appear to the BCP if the actual distribution (black curve) was categorized into 90 (blue), 30 (green) or 10 (magenta) size bins.

TAS is the true airspeed at the BCP sample area and $T$ is the sampling time. The counting efficiency of the BCP is $100 \%$ as long as there are no coincident particles in the beam since they would be counted as a single particle. Given the very small sample area of the BCP this is a very low probability event unless concentrations exceed $500 \mathrm{~cm}^{-3}$. The probability that two droplets will be in the sensitive sample volume simultaneously can be estimated using Poisson statistics. The probability of two droplets in the sample area, SA, at the same time is $P=1-e^{-\tau \lambda}$ (Baumgardner et al., 1985), where $\lambda=N \cdot$ SA . TAS. $N$ is the droplet number concentration and $\tau$ is the amount of time that a droplet spends in the BCP laser beam, that is, the beam width (average $0.1 \mathrm{~mm}$ ) divided by the TAS. In the absence of coincidence or other counting errors, $\lambda$ is the counting rate in units of droplets per second. For example when $N=500 \mathrm{~cm}^{-3}$, for droplets of diameter $10 \mu \mathrm{m}, 20 \mu \mathrm{m}$ and $30 \mu \mathrm{m}$, with sample areas of $\mathrm{SA}=0.17 \mathrm{~mm}, 0.24 \mathrm{~mm}$ and $0.28 \mathrm{~mm}$ (see Fig. $4 \mathrm{~b}$ ), the probabilities of coincidence are $0.8,1.4$ and $1.7 \%$, respectively. This would be for a BCP onboard a commercial aircraft with a cruise speed of $250 \mathrm{~m} \mathrm{~s}^{-1}$.

Hence, the source of most of the uncertainty associated with deriving the number concentration is in the determination of SA and AS. The SA, as previously discussed, is measured with the droplet mapping system with a linear position accuracy of $\pm 10 \mu \mathrm{m}$, which means that the area is estimated with a root sum square (RSS) accuracy of $\pm 14 \mu \mathrm{m}^{2}$, or $\pm 6 \%$ for a $22 \mu \mathrm{m}$ with sample area of $0.25 \mathrm{~mm}^{2}$.

The air speed at the sample area is the other variable needed to calculate the sample volume. The sensitive region of the $\mathrm{BCP}$ is $4 \mathrm{~cm}$ from the skin of the aircraft; hence, the velocity of the particles at this point will likely be slower than free airstream. Aircraft airspeed sensors, however are $6 \mathrm{~cm}$ from the skin, so if we use the measured aircraft speed in our calculations, we estimate that an uncertainty of approximately $-20 \%$ of the actual airspeed at the sample volume. In summary, the majority of the uncertainty in the derivation of the number concentration is in the sample area and airspeed. The root sum squared expected uncertainty is $\pm 21 \%$.

The other factor to take into account when estimating the concentration is the amount of time required to obtain a statistically significant sample. Using Poisson sampling theory, in order to be confident that the sample is representative of the general particle population, at least 100 particles must be measured to assure an uncertainty less than $10 \%$ $\left(n^{1 / 2} / n\right)$. To measure a concentration of $0.03 \mathrm{~cm}^{-3}$, the approximate concentration of a thin cirrus with an optical depth of 0.03 , a volume of air of $3000 \mathrm{~cm}^{3}$ must be sampled. The $\mathrm{BCP}$ discussed in this paper has an average sample area of approximately $0.25 \mathrm{~mm}^{2}$ and a commercial airliner flies at an airspeed of approximately $250 \mathrm{~m} \mathrm{~s}^{-1}$. This means that $63 \mathrm{~cm}^{3} \mathrm{~s}^{-1}$ of air is sampled and measurements would need to be accumulated over approximately $45 \mathrm{~s}$ to obtain a statistically relevant value. If a $20 \%$ uncertainty is acceptable, then only 25 particles are needed and the sampling time is reduce to $10 \mathrm{~s}$.

The accuracy with which the actual size distribution is derived is a function of five factors: (1) the number of channels in the measured size distribution, (2) the fraction of the actual size distribution with concentrations in optical diameters smaller than about $15 \mu \mathrm{m}$, (3) the width of the actual distribution, (4) the refractive index of the particles and (5) their shape. The accuracy depends upon how much of the original information contained in the actual distribution is maintained during the measurement process. The particles are being undersized over a range of values as they go through the sample area in uniformly, random locations. If they are placed in a smaller size bin, whose width is very small, then the new size has retained most of the original information. For example if a $20 \mu \mathrm{m}$ particle gets sized some of the time as a $10 \mu \mathrm{m}$ particle, and if the width of the channel for $10 \mu \mathrm{m}$ particles is only $1 \mu \mathrm{m}$, then the inversion will put that particle back into the $20 \mu \mathrm{m}$ bin. If the width of the channels in the measured distribution is $5 \mu \mathrm{m}$, the information is lost when the $20 \mu \mathrm{m}$ particle gets sized as a $10 \mu \mathrm{m}$ particle. In the process of rebinning it is placed in a channel that might also contain 7, 8 , $9,10,11$, and $12 \mu \mathrm{m}$ particles. In this case, the inversion will be unable to produce as accurate of a representation of the actual distribution since $7-12 \mu \mathrm{m}$ particles can end up in the size bins around the $20 \mu \mathrm{m}$ size bin of the retrieved distribution. The subsequent effect is a retrieved distribution that is broader than the actual.

The importance of the fraction of particles smaller than $15 \mu \mathrm{m}$ in the actual distribution and how they impact the retrieval accuracy is that, in the case of the BCP whose sample area was evaluated above, these smaller particles will be 


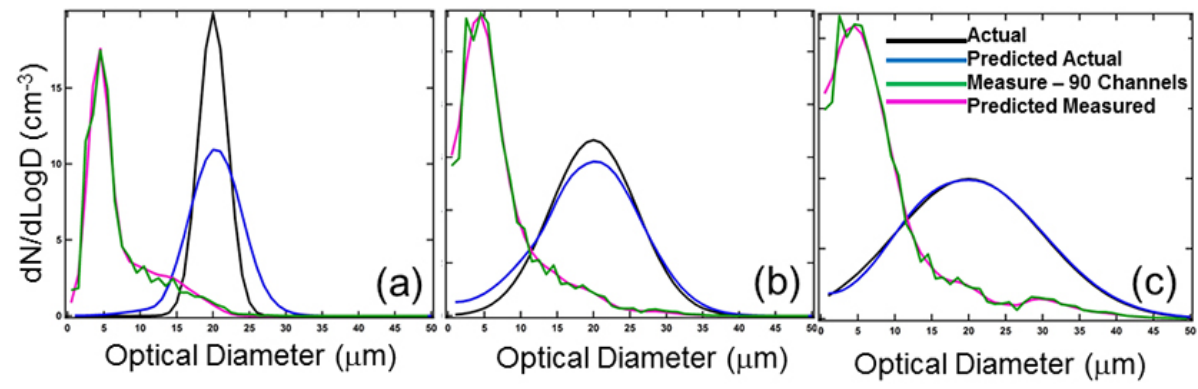

Figure 8. The three panels illustrate how the accuracy of retrieving the actual size distribution is related to the width of the distribution. The black curve is a simulated distribution with an average diameter of $20 \mu \mathrm{m}$ and standard deviation of $2 \mu \mathrm{m}, 6 \mu \mathrm{m}$ and $10 \mu \mathrm{m}$ in panels (a), (b) and (c) respectively. The blue curves are the distributions retrieved from the simulated measurements shown in green and the red curve shows the predicted measurement after the inversion.

lost when they go through the edges of the beam. Hence, information from the actual distribution is lost from the small particle sizes that cannot be completely retrieved since we do not know a priori what the shape of the actual distribution will be.

The third parameter that limits the accuracy of the retrieval is the width of the actual size distribution. This is also an issue of information loss. The most rigorous test of a retrieval is that of a mono-dispersed particle distribution whose measured distribution would look similar to one of the probability distributions that were shown in Fig. 6 if the channels of the measured distribution have very narrow widths so as to capture the detailed structure of the many possible measured sizes. Due to the finite widths of the measured distributions, however, these structures are smoothed out so that the subsequent inversion produces a retrieved distribution broader than mono-dispersed. When the actual distribution is broader, the resultant distribution that is measured is the mixture of probabilities that also smooth the intrinsic shape of the probability distributions. The retrieval is able to better reproduce the broader actual distribution as illustrated in Fig. 8. Here the actual distribution is simulated with a Gaussian probability distribution with a constant concentration and average diameter of $100 \mathrm{~cm}^{-3}$ and $20 \mu \mathrm{m}$, respectively. The standard deviations are set to $2 \mu \mathrm{m}, 6 \mu \mathrm{m}$ and $10 \mu \mathrm{m}$. The black curves are the simulated actual distributions; the green curves are the simulated "measured" distributions, assuming a 90 channel simulated "measured" distribution. The simulated "measured" distribution is similar to that illustrated in Fig. 6 where the simulated actual distribution is multiplied by the transformation matrix. The blue and red curves show the simulated actual and "measured" distributions following application of the inversion.

Figure 9 shows the result of evaluating a range of simulated actual and "measured" size distributions. The number of channels of the simulated measured distributions, the average diameter and the standard deviation of the distribution are varied in order to evaluate the accuracy of the retrieval with respect to the three factors discussed above. The error is

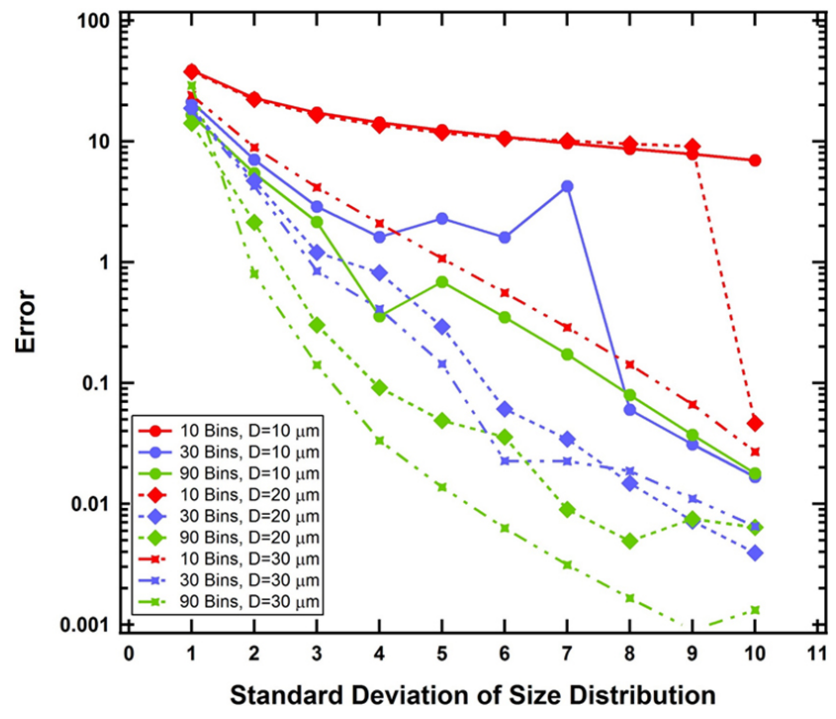

Figure 9. The sets of curves shown in this figure illustrate the accuracy of the inversion as a function of the standard deviation of the simulated actual (Gaussian) size distribution. Each color represents a simulated, measured size distribution binned in 10 channels (red), 30 (blue) and 90 (green). The average diameter of the simulated actual distribution is varied from $10 \mu \mathrm{m}$ (solid curves), $20 \mu \mathrm{m}$ (dashed) and $30 \mu \mathrm{m}$ (dot-dash).

calculated as the average squared difference between the simulated and retrieved actual distributions. In this figure we see that regardless of average diameter and number of channels in the simulated measurement, the error decreases exponentially in most cases with increasing standard deviation. The second observation is that increasing the number of channels in the measurement decreases the error significantly. The increasing of the average diameter, that is, moving the majority of the particles to sizes larger than the threshold size, also decreases the error. The largest effect is when measuring with a small number of size channels. 


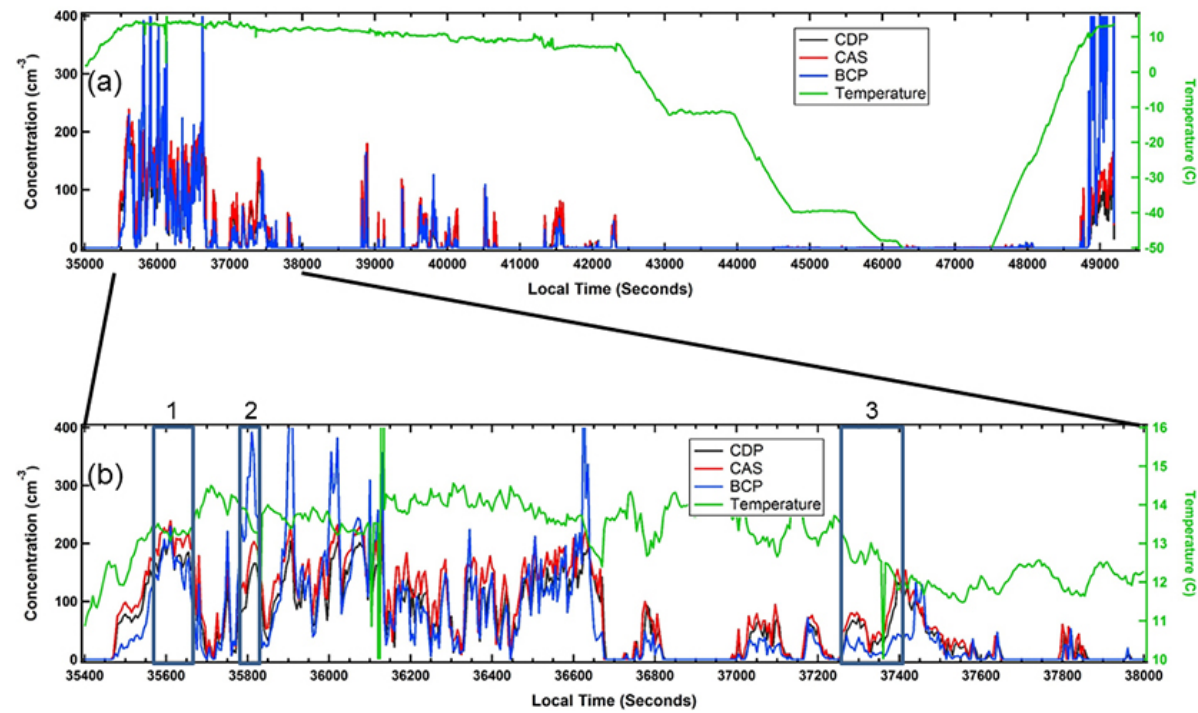

Figure 10. In this time series of cloud particle concentrations, the cloud droplet probe (CDP (black), cloud and aerosol spectrometer (CAS) (red) and backscatter cloud probe (BCP) (blue) are compared over the entire flight of the BAE-146 on 14 September 2011 in the top panel and over the liquid-water segment of the cloud in the lower panel. The green curve is the ambient temperature. The numbered boxes are cloud segments where size spectra averages are calculated and displayed in Fig. 12.

\section{Flight results}

The measurements on the BAE-146, operated by FAAM, were made in September, 2010, on flights over the North Atlantic as part of the IAGOS-DS and Septex Cloud-Radiation projects (http://www.faam.ac.uk/index.php/home). Measurements were made through a range of cloud types and temperatures from which one example is highlighted here. As was previously shown in Fig. 3a, the BCP was mounted on the forward, starboard window-blank no. 3 located $\sim 5 \mathrm{~m}$ from the aircraft nose upstream of the aircraft's Johnson-Williams hot-wire total liquid-water content probe. In addition to the $\mathrm{BCP}$, there were other cloud microphysical optical spectrometers flown, including the DMT cloud droplet probe (CDP) that has been described by Lance et al. (2010) and a cloud and aerosol spectrometer (CAS) described by Baumgardner et al. (2001). The CDP, CAS and other 2-D optical array probes were mounted on the starboard wing pylons, $8 \mathrm{~m}$ aft of the $\mathrm{BCP}$.

Figure 10a is a time series of number concentrations from the BCP, CDP and CAS during a $4 \mathrm{~h}$ flight (B553 using the FAAM research flight designation) conducted on 14 September 2010 . Figure $10 \mathrm{~b}$ shows the same variables but over the time period 35000-38000 UTC seconds from start of the day. This was a period when the aircraft was penetrating clouds that were all liquid water. The concentrations from the CAS, that measures in the size range from 0.5 to $50 \mu \mathrm{m}$, and from the CDP, which measures from 2.0 to $50 \mu \mathrm{m}$, were calculated over the same size range as that of the $\mathrm{BCP}$ used during this project (ca. 4 to $45 \mu \mathrm{m}$ ). As previously noted, without an airspeed measurement at the location of the $\mathrm{BCP}$ sample area, there is an uncertainty of approximately $20 \%$ in calculating the sample volume, that is, although we are using the recorded aircraft true airspeed to calculate the $\mathrm{BCP}$ sample volume, the actual volume could be as much as $20 \%$ smaller. In the majority of the cloud passes during this $50 \mathrm{~min}$ period of sampling the BCP measured concentrations that were within $20 \%$ of those derived from the CDP and CAS. During the period from 35700 to 36150 , the BCP would occasionally increase to almost a factor of two greater than the other two spectrometers. During the period from 37000 to 37600 , the BCP concentrations were about half of those from the other two instruments.

Figure 11a and b compare the liquid-water content (LWC) and optical median-volume diameter (MVD) from the three probes for the same time periods as shown in Fig. 10b. As with the concentrations, the BCP LWC is generally in good agreement with the other two spectrometers except during the same time periods where the number concentrations deviated. The BCP MVD falls between those of the CDP and CAS except for the period from 37000 to 37600 when the CDP and CAS MVDs increase but the BCP MVD remains about what it had been throughout the period.

An additional method to evaluate how well the BCP measures cloud droplets in relationship to the CDP and CAS is to compare the size distributions. Figure 12 illustrates size distributions from the three instruments for three time intervals that are indicated as boxes numbered 1, 2 and 3 in Fig. 10b. These three intervals were chosen to evaluate periods when the BCP concentrations were (1) within $20 \%$ of those from the CDP and CAS, (2) much greater than the other two instruments and (3) much less than the other two. For the first 

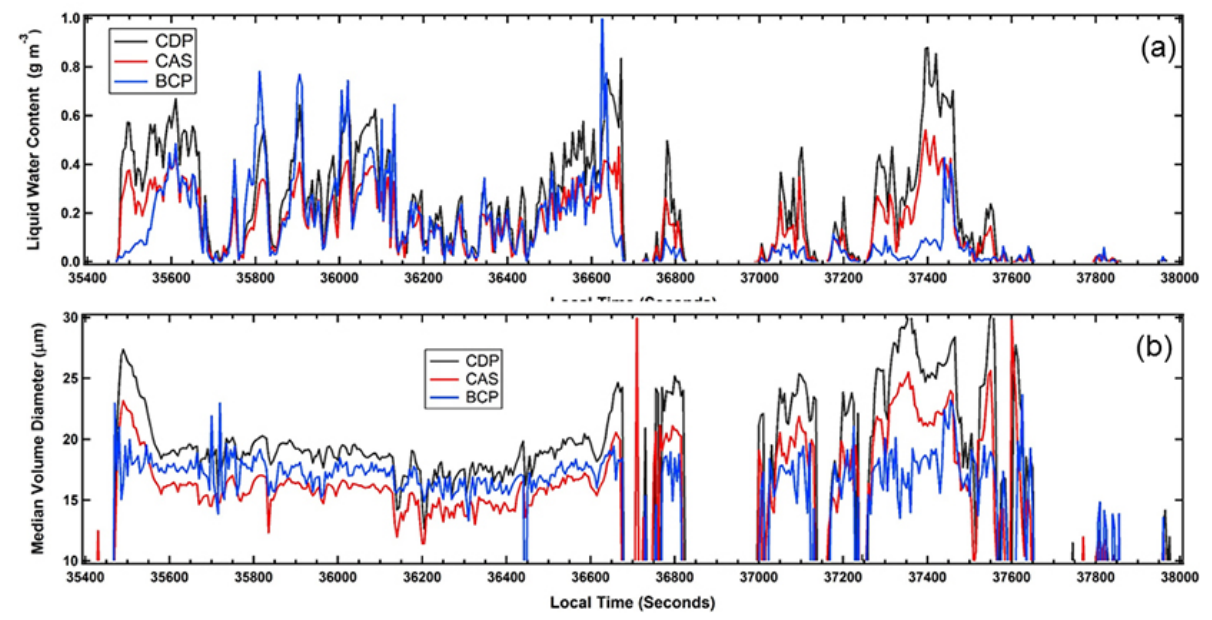

Figure 11. These time series of liquid-water content (LWC) in the top panel and optical median volume diameter (MVD) in the lower panel are over the same interval of time as shown in Fig. 10b.

case, Fig. 12-1, the BCP size distributions falls almost on top of that from the CAS for droplet diameters larger than $10 \mu \mathrm{m}$ and overestimates the concentration of smaller droplets. The $\mathrm{CDP}$ size distribution is narrower than those from the $\mathrm{BCP}$ and CAS. In the second time interval over which the measurements were averaged and in which the $\mathrm{BCP}$ was much higher in concentrations, we see in Fig. 12-2 that the BCP is higher in concentration over the entire size range. The CAS also exceeds the CDP over all sizes, although not to the same degree as the BCP. For the case when the BCP concentrations and MVDs were smaller than the CDP and CAS (time interval 3), we see from Fig. 12-3 that the peak in the size distribution from the BCP falls to the left of both of the other spectrometers. The concentrations are also much less at all sizes. It should be pointed out that the CAS and the CDP are not necessarily providing the "correct" answer and the purpose of these intercomparisons is to evaluate the BCP against spectrometers that have been in use for a longer period of time. As can be seen from these examples the CDP and CAS are not in perfect agreement; however, the differences remain approximately the same in all three time intervals, whereas the BCP differs in a manner that cannot be explained at this time.

Two BCPs were delivered to the IAGOS management team for installation on a Lufthansa A340-300 "Viersen" airliner in May, 2011, along with the rest of the IAGOS instrument package (O3, $\mathrm{CO}, \mathrm{CO} 2, \mathrm{NOy}, \mathrm{NOx}, \mathrm{H} 2 \mathrm{O})$. The $\mathrm{BCP}$ was mounted next to the inlets for the aerosol and gas analyzers as shown in the photographs in Fig. 3c and d.

The first test flight of the Viersen with the IAGOS package took place in July, 2011, and routine operation began in September, 2011. Additional IAGOS systems were installed on a China Airlines A340 "B-18806", an Air France A340 "F-GLZU", a Cathay Pacific A340 "B-HLR" and an Iberia A340 "EC-GUQ" in 26 June 2012, and June, August and

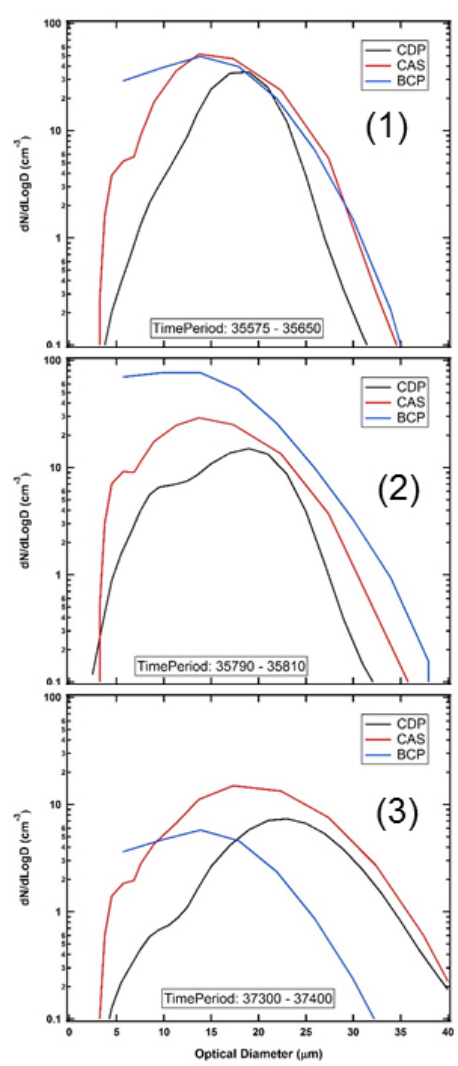

Figure 12. The size distributions shown here illustrate how the backscatter cloud probe (BCP) compares with the cloud droplet probe (CDP) and cloud and aerosol spectrometer (CAS). The spectra were averaged over the three time periods marked with boxes in Fig. 10b when the aircraft was in a liquid-water cloud. The BCP has 10 channels (blue), whereas the CDP (black) and CAS (red) have 30 channels. 


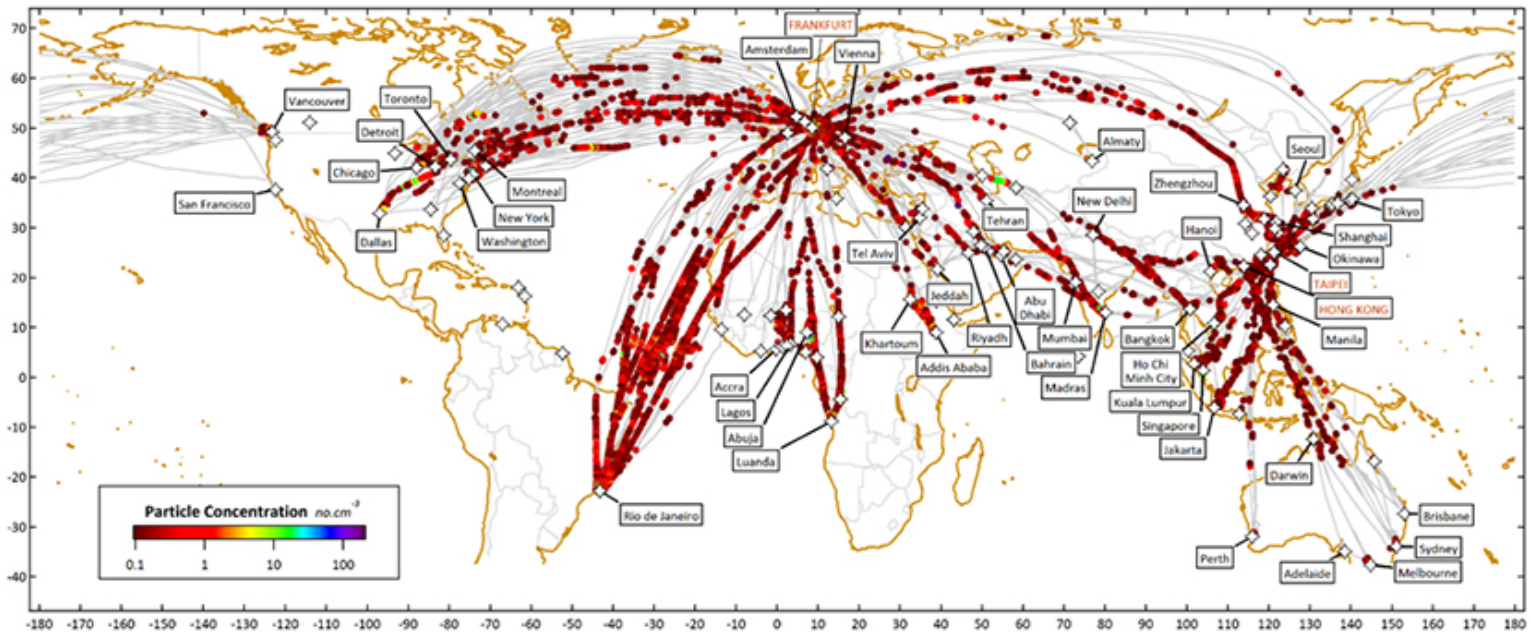

Figure 13. The trajectories for the Lufthansa (September, 2011-March, 2013) and China Airlines (January-March, 2013) commercial flights are shown here encoded with cloud encounters (colored, filled circles) and locations of arrivals and departures (yellow diamonds). The color scale shows the number concentrations of the clouds that were identified.

October of 2013, respectively. The BCPs on these commercial aircraft is sampled at $0.25 \mathrm{~Hz}$ and transmits ten channel size distributions. Ten channels were chosen to minimize the amount of data that were recorded and prevent filling the storage device. The data are recorded during several flights then routinely downloaded by IAGOS technical staff.

As of March, 2013, the BCPs had taken data on a total of 1211 flights, representing $7357 \mathrm{~h}$ of flight time during which 340 of those hours had been in cloud. We define a cloud as one with a number concentration greater than $0.01 \mathrm{~cm}^{-3}$ for more than 20 seconds (five samples from the BCP). Figure 13 summarizes the trajectories of all the flights for the 18 months covering 1 September, 2011, to the end of March, 2013. Table 1 list some basic statistics with respect to the regions that were covered by the flights.

Figure 14 and 15 are expanded views of the flights between Europe and North America and Europe and South America, respectively. These two regions are highlighted because flights covering these regions are the longest in duration and $70 \%$ of these flights also encountered clouds at cruise altitude. More than $90 \%$ of the flights from Frankfurt to Rio encountered clouds at cruise altitude. The Asia routes (not shown here), although somewhat shorter in duration, also encountered clouds at cruise altitude during more than $70 \%$ of the flights.

\section{Discussion}

Although the $\mathrm{BCP}$ was originally designed as a cloud indicator, its design includes a method to estimate the effective optical diameter (EOD) of individual particles. The EOD is the diameter that a spherical water droplet would have if it scattered the same amount of light that was measured. The derivation of the EOD is complicated by the Mie scattering ambiguities and the non-uniform incident laser intensity that requires an inversion of the data to derive the EOD. The size distributions from the $\mathrm{BCP}$, along with the number concentration, LWC and MVD, were compared with two other single particle spectrometers. The BCP was generally within $20 \%$ of the other sensors except for several time periods when it either overestimated or underestimated the bulk parameters. The source of the differences cannot be explained but there are a number of possible causes.

One of the major uncertainties when interpreting the measurements is that of the airflow velocity at the sample volume of the BCP. The viewing volume of the BCP is outside the boundary layer of the air near the surface of the aircraft. If it was within the boundary layer it would see very few particles. There have been numerous modeling and observational studies of airflow effects on particle measurements (King, 1984; King et al., 1984; Norment, 1988; Twohy and Rogers, 1993). These studies show that the airspeed decreases as you approach the skin of the aircraft and that the compression of the streamlines leads to size sorting. Particles less than $20 \mu \mathrm{m}$ tend to follow the streamlines whereas larger droplets partially cross them. The subsequent effect is that particles larger than $20 \mu \mathrm{m}$ appear to have concentrations larger than their actual values so that they are overestimated. For example, Twohy and Rogers (1993) show that droplets with diameters of $50 \mu \mathrm{m}$ are enhanced by a factor of two over actual. We have assumed in our calculations of sample volume that the airspeed at the BCP sample area is the same as measured for the aircraft in order to derive the concentrations on the Airbus A340-300 aircraft. As we have no other cloud probe to compare with, or measurements of the airspeed at that point, the uncertainty could be as much as $-20 \%$. Likewise, without doing the airflow modeling, such as has been 


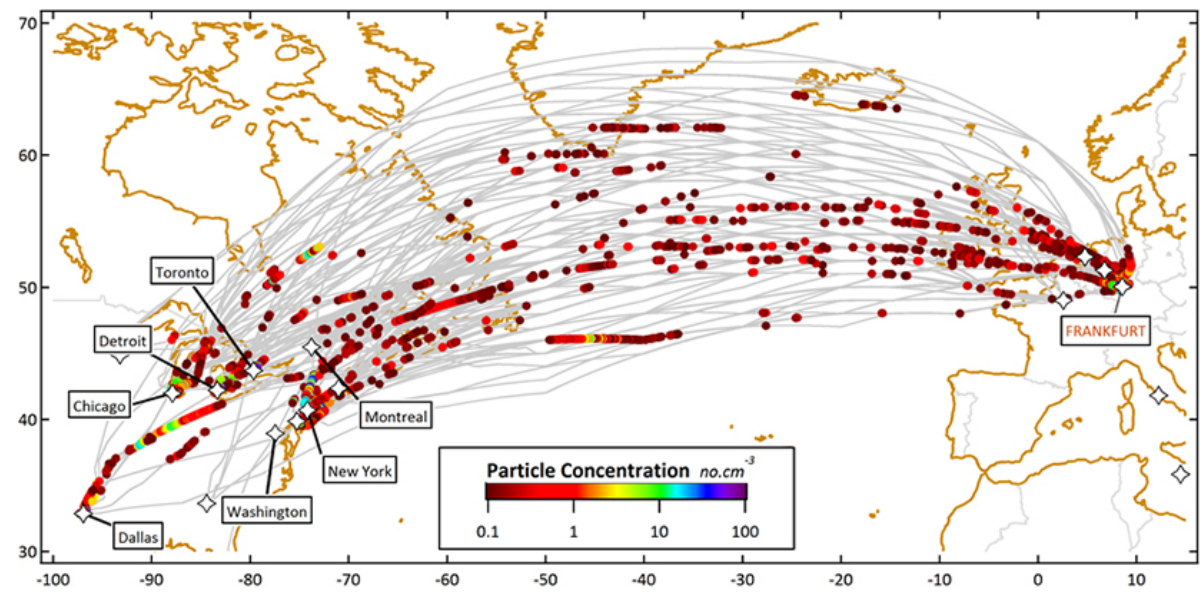

Figure 14. Similar to Fig. 13, but expanded to show only the flights between Europe and North America.

Table 1. Cloud statistics from Airbus A340-300 BCP measurements. Number concentrations $>0.01 \mathrm{~cm}^{-3}$ define a cloud.

\begin{tabular}{|c|c|c|c|c|c|c|c|}
\hline Region & $\begin{array}{r}\text { Total } \\
\text { flights }\end{array}$ & $\begin{array}{l}\text { Total } \\
\text { flight } \\
\text { hours }\end{array}$ & $\begin{array}{r}\text { Total time } \\
\text { in cloud }\end{array}$ & $\begin{array}{r}\text { Fraction of } \\
\text { flight hours } \\
\text { in cloud }(\%)\end{array}$ & $\begin{array}{r}\text { Fraction of flights } \\
\text { with cloud } \\
\text { encounters at } \\
\text { cruise altitude }(\%)\end{array}$ & $\begin{array}{r}\text { Fraction of } \\
\text { flights with } \\
\text { cloud encounters } \\
\text { at takeoff }(\%)\end{array}$ & $\begin{array}{r}\text { Fraction of } \\
\text { flights with } \\
\text { cloud encounters } \\
\text { at landing }(\%)\end{array}$ \\
\hline Africa & 85 & 453 & 34.9 & 7.7 & 62 & 54 & 61 \\
\hline America & 128 & 1035 & 48.9 & 4.7 & 70 & 62 & 69 \\
\hline Asia & 103 & 895 & 49.3 & 5.5 & 73 & 64 & 62 \\
\hline Europe & 40 & 462 & 5.0 & 1.1 & 10 & 45 & 58 \\
\hline Far East & 391 & 1390 & 53.5 & 3.8 & 24 & 46 & 53 \\
\hline Gulf & 176 & 769 & 25.6 & 3.3 & 19 & 39 & 42 \\
\hline Middle East & 111 & 462 & 17.2 & 3.7 & 26 & 42 & 47 \\
\hline Pacific & 64 & 669 & 8.4 & 1.3 & 13 & 41 & 38 \\
\hline Rio & 99 & 1117 & 97.9 & 8.8 & 94 & 76 & 80 \\
\hline All & 1211 & 7357 & 340 & 4.6 & 40 & 50 & 55 \\
\hline
\end{tabular}

done for various research aircraft to locate optimum mounting positions for cloud probes, we do not know what type of enhancements might be occurring in the concentrations at various aerodynamic diameters. At some locations on the aircraft there can also be a "shadow zone", where the boundary layer has grown to a thickness sufficient to carry cloud particles outside of the sensing volume of an instrument. This is apparently not the case for either the measurements on the BAE-146 or the Airbuses given that the BCP is detecting cloud particles.

Ice-crystal shattering is another source of uncertainty and measurement error. A number of studies have highlighted the issue of ice crystals shattering and water droplets splattering on the leading edges of instruments (e.g., Engblom and Ross, 2003; Korolev et al., 2013), leading to artificially created particles that confound the measurements. The geometry of the BCP, that is, lack of any leading edges for droplets or crystals to impact and break, means that the instrument itself will be free of probe-induced artifact; however, the fuselage of the aircraft provides a large surface for cloud particles to strike and shatter into smaller fragments. The results from the BAE-146 were from measurements in warm clouds. There might have been splashing but the time series of the concentrations (Fig. 10b) do not seem to indicate any systematic bias. The BCP indicated much higher concentrations during several of the cloud penetrations. These might have been a result of satellite droplets from splashing but lacking any additional information we can only speculate at this point. The high concentrations sometimes seen in the $\mathrm{BCP}$ measurements on the Airbus are likely the result of enhancement due to crystal breakup. For example in Fig. 15, during the flights between Frankfurt and Rio de Janeiro, over the Intertropical Convergence Zone, the number concentrations sometimes exceed $100 \mathrm{~cm}^{-3}$. This is a very high concentration for cirrus clouds. Temperatures are always below freezing in cirrus clouds at the aircraft cruising altitude. Cirrus crystals, although usually quite small $(<50 \mu \mathrm{m}$ at very cold 


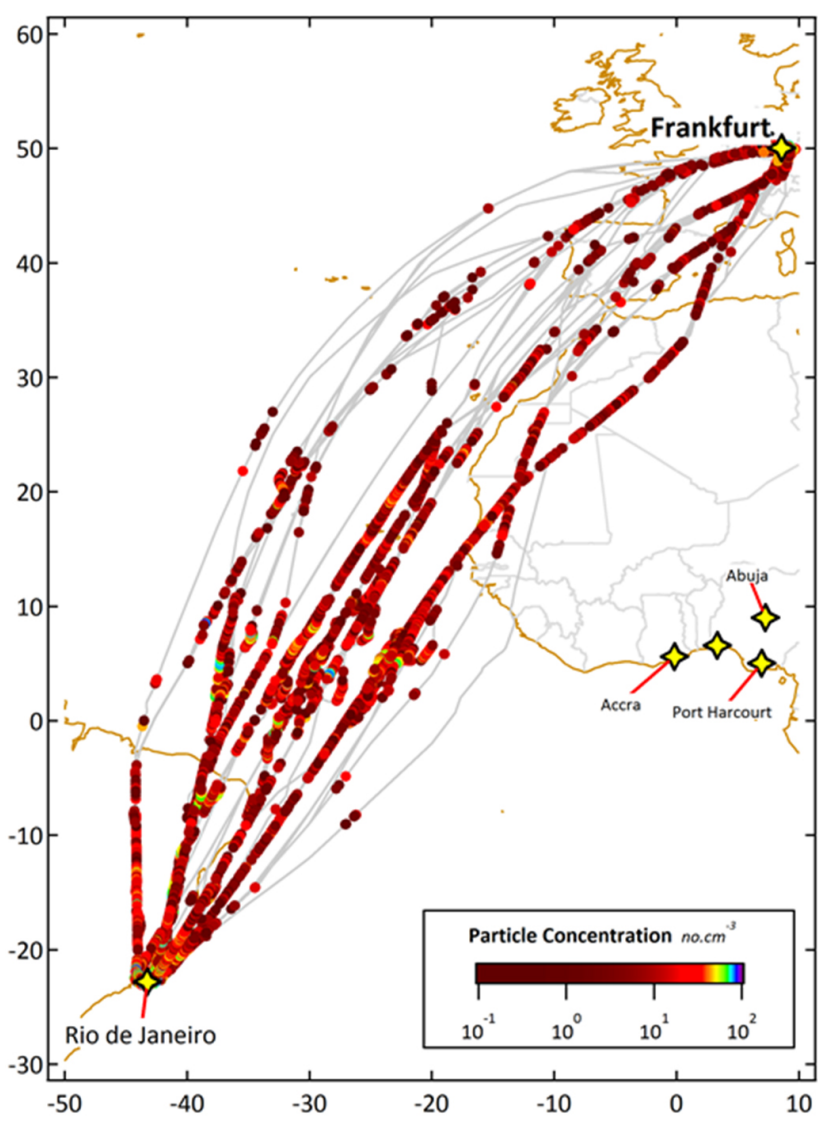

Figure 15. Similar to Fig. 13, but expanded to show only the flights between Europe and Rio de Janeiro.

temperatures), can sometimes grow to sizes large enough to fracture on impact.

The comparison of the $\mathrm{BCP}$ with the $\mathrm{CDP}$ and CAS on the BAE-146 was encouraging from two aspects: (1) the number and mass concentrations generally compared within $20 \%$ over the whole flight and (2) the size distributions were in good agreement with respect to peaks and shapes. This gives us confidence that a measurement so close to the aircraft skin can give a reasonable representation of the cloud properties and that the inversion technique is robust enough to extract size information.

The preliminary analysis from the $\mathrm{BCP}$ on the commercial passenger airliners shows an abundance of cloud data and a wealth of information that can be extracted on cloud microphysical properties in the size range of the $\mathrm{BCP}$. The caveat is that care must be taken when ice shattering may be a potential source of artifacts. A detailed analysis of these data is well beyond the scope of this paper where we have focused on the technical aspects of the BCP. That being said, a cursory look at some of the regions of the world where desert dust and clouds are encountered offer a tantalizing hint of the types of information that can be obtained. These are data that can be used to compare with satellite measurements

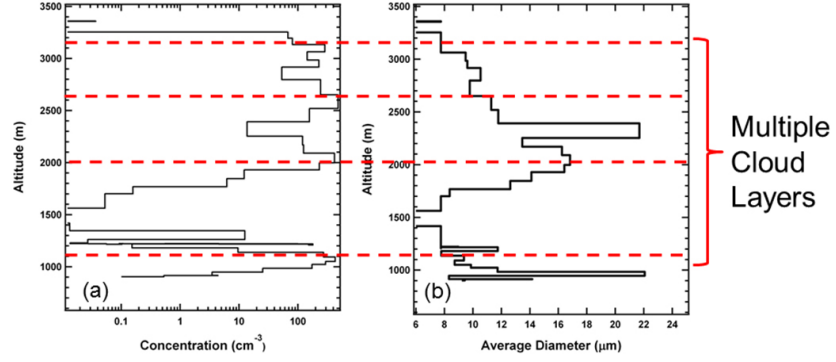

Figure 16. These vertical profiles of the number concentration in the left panel and average optical diameter in the right panel are an example of multilayered clouds (red horizontal lines) measured with the backscatter cloud probe as the aircraft was landing in Frankfurt, Germany in May, 2011. Cloud layers are delineated by the peaks in concentration greater than $100 \mathrm{~cm}^{-3}$.

and to validate climate and cloud/dust models. Looking at the flight trajectories from Frankfurt to Rio de Janeiro in Fig. 15, we see that there are many clouds and quite a few with concentrations greater than $1 \mathrm{~cm}^{-3}\left(1000 \mathrm{~L}^{-1}\right)$. More than a $1000 \mathrm{~L}^{-1}$ is an enormously high concentration of ice crystals for cirrus, the type of cloud that would normally be found at these altitudes and temperatures. Such large concentrations have been measured (Jensen et al., 2013); however, it is more likely that the ice-crystal concentration is being multiplied by breakup on the fuselage. From the point of view of better understanding ice cloud microphysics, these high, artificial concentrations obscure some of the important features of these clouds. From the viewpoint of aircraft flight operations, such high concentrations are potential hazards as these crystals and their fragments are the very type of cloud particles that have been documented as obstructing inlets to temperature sensors and pitot tubes that measure air speed. These measured high concentrations are found not only over the same route where documented aircraft incidents have happened, but also over many other regions of the world. This underscores the importance of having this type of information available in real time for flight crews to make informed decisions.

The vertical structure of clouds is also an important measurement and each flight has vertical profiles during takeoff and landing. As shown in Table 1,50\% of the take offs and $55 \%$ of the landings encountered clouds (i.e., more than 600 vertical profiles of cloud structure are currently in the database). These are data that can be used to compare with radar, lidar and satellite measurements, as well as providing useful climatology for use in climate and weather forecast models. Figure 16 illustrates one such vertical profile of cloud structure as the aircraft was landing at the Frankfurt airport in May, 2012. Figures 16a and b show the vertical structure of the number concentration and MVD, respectively. The horizontal red lines mark four distinct layers, over an altitude range of $2000 \mathrm{~m}$, where the number concentrations peaked and values were greater than $100 \mathrm{~cm}^{-3}$. 


\section{Summary and conclusions}

A compact, lightweight single particle cloud spectrometer, the backscatter cloud probe (BCP) is described that operates autonomously and measures the number concentration of particles in the equivalent optical diameter (EOD) range nominally from 5 to $75 \mu \mathrm{m}$. The size distributions are derived from the measurement using an inversion technique that requires detailed information about the intensity distribution of the BCP sample area that is obtained using measurements with a mono-dispersed droplet stream.

The comparison of the $\mathrm{BCP}$ with two other spectrometers, the CDP and CAS, show that the BCP, whose active sample volume is only $4 \mathrm{~cm}$ from the aircraft skin, generally agrees within $20 \%$ in number concentration and size distributions measured with the other two spectrometers.

The BCPs on two commercial airliners, Lufthansa and China Airlines Airbus A340-300s, have taken more than $7000 \mathrm{~h}$ of data during more than $1200 \mathrm{~h}$ of flight time. At a cruise altitude between 9 and $11 \mathrm{~km}, 40 \%$ of the flights encountered cirrus and $50 \%$ of the take offs and landing were made through cloud layers. The 340 total hours of cloud data and more than 600 vertical profiles through cloud are a valuable database of information that provide measurements that can complement those from remote sensors like radar, lidar and satellites, as well as being useful for validating algorithms for extracting microphysical properties from remotesensing measurements. As with data from any cloud spectrometer in conditions of high ice concentration, care must be taken when interpreting any data sets where ice shattering on the fuselage may produce artifacts in the measurements.

In addition to the value for research on cloud properties, the data also provides important information to the aircraft industry on statistics related to the frequency of flight encounters with high-ice-crystal concentrations, events that pose potential hazards to flight operations.

Acknowledgements. The authors would like to thank the staff of the Facility for Airborne Atmospheric Measurements (FAAM), Bill Dawson, Roy Newton and Gary Granger of Droplet Measurement Technologies and Lufthansa and China Airlines for their cooperation in partnering with IAGOS to make these invaluable environmental measurements. Financial support of the instrument development, installation and operation from the European Commission projects IAGOS-DS and IAGOS-ERI, national agencies in Germany (BMBF), France (MESR), and the UK (NERC), and the IAGOS member institutions (http://www.iagos.org/partners) is gratefully acknowledged. The calibration work was supported by the National Oceanic and Atmospheric Administration (NOAA) climate and air quality programs. Finally we would like to than David Delene and Gabor Vali for their detailed reviews that greatly improved the quality of this manuscript.

Edited by: P. Herckes

\section{References}

Baumgardner, D., Strapp, W., and Dye, J. E.: Evaluation of the Forward Scattering Spectrometer Probe - Part II: Corrections for coincidence and dead-time losses, J. Atmos. Ocean. Tech., 2, 626632, 1985.

Baumgardner, D., Jonsson, H., Dawson, W., O'Connor, D., and Newton, R.: The cloud, aerosol and precipitation spectrometer (CAPS): A new instrument for cloud investigations, Atmos. Res., 59-60, 251-264, 2001.

Engblom, W. A. and Ross, M. W.: Numerical Model of Airflow Induced Particle Enhancement for Instruments Carried by the WB57 Aircraft, NASA Aerospace Report No. ATR-2003(5084)-01, 29 pp., 2003.

Gayet, J. F., Febvre, G., Brogniez, G., Chepfer, H., Renger, W., and Wendling, P.: Microphysical and Optical Properties of Cirrus and Contrails: Cloud Field Study on 13 October 1989, J. Atmos. Sci., 53, 126-138, 1996.

Jensen, E. G., Diskin, G., Lawson, R. P., Lance, S., Bui, T. P., Hlavka, D., McGille, M., Pfister, L., Toon, O. B., and Gao, R.: Ice nucleation and dehydration in the Tropical Tropopause Layer, P. Natl. Acad. Sci., 110, 2041-2046, 2013.

King, W.: Air flow and particle trajectories around aircraft fuselages. I: Theory, J. Atmos. Ocean. Tech., 1, 5-13, 1984.

King, W., Turvey, D., Williams, D., and Llewellyn, D.: Air flow and particle trajectories around aircraft fuselages. II: Measurements, J. Atmos. Ocean. Tech., 1, 14-21, 1984.

Korolev, A. V., Kuznetsov, S. V., Makarov, Y. E., and Novikov, V. S.: Evaluation of Measurements of Particle Size and Sample Area from Optical Array Probes, J. Atmos. Oceanic Tech., 8, 514-522, 1991.

Korolev, A. V., Emery, E. F., Strapp, J. W., Cober, S. G., and Isaac, G. A.: Quantification of the effects of shattering on airborne ice particle measurements, J. Atmos. Ocean. Tech., 30, 2527-2553, 2013.

Lance, S., Brock, C. A., Rogers, D., and Gordon, J. A.: Water droplet calibration of the Cloud Droplet Probe (CDP) and inflight performance in liquid, ice and mixed-phase clouds during ARCPAC, Atmos. Meas. Tech., 3, 1683-1706, doi:10.5194/amt3-1683-2010, 2010.

Markowski, G. R.: Improving Twomey's Algorithm for Inversion of Aerosol Measurement Data, Aerosol Sci. Technol., 7, 127-141, 1987.

Mie, G.: Beiträge zur Optik trüber Medien, speziell kolloidaler Metallösungen. Annalen der Physik, Vierte Folge, Band 25, No. 3, 377-445, 1908.

Nagel, D., Maixner, U., Strapp, W., and Wasey, M.: Advancements in Techniques for Calibration and Characterization of In Situ Optical Particle Measuring Probes, and Applications to the FSSP-100 Probe, J. Atmos. Ocean. Tech., 24, 745-760, doi:10.1175/JTECH2006.1, 2007.

Norment, H.: Three-dimensional trajectory analysis of two drop sizing instruments: PMS OAP and PMS FSSP, J. Atmos. Ocean. Tech., 5, 743-756, 1988.

Rossow, W. B., Zhang, Y.-C., and Wang, J.: A statistical model of cloud vertical structure based on reconciling cloud layer amounts inferred from satellites and radiosonde humidity profiles, J. Climate, 18, 3587-3605, doi:10.1175/JCLI3479.1, 2005. 
Sassen, K., Griffin, M. K., and Dodd, G. C.: Optical scattering and microphysical properties of subvisible cirrus clouds, and climatic implications, J. Appl. Meteorol., 28, 91-98, 1989.

Twohy, C. and Rogers, D.: Airflow and water drop trajectories at instrument sampling points around the Beechcraft King Air and Lockheed Electra, J. Atmos. Ocean. Tech., 10, 566-578, 1993.
Twomey, S.: Introduction to the Mathematics of Inversion in Remote Sensing and Indirect Measurements, Developments in Geomathematics 3, Elsevier Scientific Publishing Company, Amsterdam, 237 pp., 1977.

Wendisch, M., Keil, A., and Korolev, A. V.: FSSP Characterization with Monodisperse Water Droplets, J. Atmos. Ocean. Tech., 13, 1152-1165, 1996. 